\title{
O AMOR E SUAS REGRAS EM "SOBRE VERSOS DE VIRGÍLIO"
}

\author{
Telma de Souza Birchal* \\ tbirchal@gmail.com
}

Cupido é um deus traiçoeiro: (...) sua glória é que seu poder se choque contra qualquer outro poder e que todas as outras regras cedam às suas (III, 5, 871/129). ${ }^{1}$

RESUMO $O$ presente artigo consiste em uma leitura do capitulo "Sobre versos de Virgílio". A primeira parte compara o amor com a amizade, questionando a tese de que a superioridade da última em relação ao primeiro é afirmada sem reservas por Montaigne. A segunda parte desenvolve uma interpretação do capítulo guiada pelas noções de "regra", "lei", "norma" e seus correlatos e identifica, a partir das diferentes perspectivas com que Montaigne aborda o assunto, três tipos de "regra": as regras dos homens, as do amor e as do próprio autor dos Ensaios. Pretendemos mostrar que, embora fale muito das mulheres, o capitulo é, sobretudo, uma reflexão sobre a condição masculina.

Palavras-chave lei, regra, amor, sexo, mulheres.

* Professora do Departamento de Filosofia da UFMG. Artigo submetido em 28/05/2012 e aceito em 27/07/2012.

1 As citações dos Ensaios de Montaigne seguem a tradução brasileira de Rosemary C. Abílio, eventualmente modificada. As referências indicam, em sequência, o número do livro em algarismos romanos e, em arábicos, a página da edição Villey-Saulnier (PUF) e a da referida tradução brasileira. 
ABSTRACT This paper presents a reading on the chapter "Upon some verses of Virgil". Its first part compares love and friendship and questions the thesis that for Montaigne the latter is superior to the former. The second part consists of an interpretation of the chapter guided by the notions of "rule", "law", "norm" and their correlates, and identifies, taking into account the different perspectives in which Montaigne develops the matter, three different kinds of rules - those of men, those of love and those of the Essays' author himself. It intends to show that, although "Upon some verses of Virgil" is a chapter that speaks much about women, it is mainly a reflexion about men and the masculine condition.

Keywords law, rule, love, sex, women.

"Sobre versos de Virgílio" é um capítulo dos Ensaios que sempre me seduziu - e do qual mantive cautelosa distância, temerosa de enfrentar um assunto tão "de carne e osso". Esperei então passar meu décimo lustro ${ }^{2}$, na esperança de, um pouco mais sábia, poder comentá-lo como merece. A exemplo de meu escritor, porém, acredito que o único efeito da passagem do tempo foi o de tornar-me mais velha ${ }^{3}$. Vamos, então, como podemos, ao nosso assunto.

"Sobre versos de Virgílio" não é, de fato, um ensaio sobre o amor, se entendemos "amor" tal como o apresenta a tradição filosófica, sobretudo a partir de Platão e do neoplatonismo. No Fedro e n' O Banquete, Eros é espiritualizado: ele ama, sobretudo, a alma, a sabedoria ou o Bem. O que escreve Montaigne também se distancia do amor cortês dos romances da literatura medieval, irrealizável, no qual a figura da mulher é inatingível, e em cujo horizonte se encontra a morte. Muito menos ainda se trata do amor conjugal, celebrado pela tradição clássica na fidelidade de Penélope e sacramentado pelo cristianismo, que lhe deu o sentido simbólico da união de Cristo e sua Igreja. Em suma, Montaigne não está falando do amor, mas de sexo; não do Eros que transcende o corpo, mas de Vênus; ele ensaia sobre o amor em sua dimensão física, tal como aparece nos versos da Eneida de

2 Idade da qual fala Montaigne, com ironia, através de versos Horácio. Ver III, 5, 886/152.

3 "Depois de um longo período de tempo, estou mais velho, porém mais sábio disso não estou certo nem uma polegada! (III, 9, 964/268). 
Virgílio e de Da natureza Lucrécio. Se algo há de divino no amor do qual fala Montaigne, trata-se da força irresistível do Eros do Olimpo, descrita por Hesíodo: "dos Deuses todos e dos homens todos ele doma no peito o espírito e a prudente vontade" .

Daqui por diante, talvez por elegância, vou usar na maior parte das vezes a palavra "amor", mas sabendo que o que está em jogo é sempre o sexo. Montaigne explica que exclui do capítulo as grandes histórias de fidelidade matrimonial ou de virtude, pois está falando de "exemplos de brilho mais banal" (exemples de lustre vulgaire)" (III, 5,868/124).

Deste longo ensaio, que trata de seu tema por tantos vieses - velhice, poesia, casamento, aparências e hipocrisias, diferenças entre homens e mulheres, a lógica do desejo - gostaria de destacar dois pontos e de defender duas teses:

1 - "Sobre versos de Virgílio" leva-nos a relativizar ou a colocar em perspectiva uma afirmação que é tida, em geral, como uma das poucas indiscutíveis nos Ensaios: a de que o amor é incomparável à amizade, ou, nos termos do nosso compositor tropical, "esta lhe é superior"5. O capítulo dedicado a La Boétie é enfático ao descrever a verdadeira amizade como a mais perfeita e altiva das relações humanas, pois é livre, se dá entre iguais, é uma experiência completa e duradoura. Tentaremos mostrar que, se podemos conceder que a amizade é superior ao amor por ser constante, rara e relacionada com a virtude, o amor, em sua humilde inferioridade, em sua inconstância, em sua onipresença que não faz distinção entre pessoas, em sua vizinhança de pequenos e mesmo de grandes vícios é, digamos assim, mais essencial e, quem sabe, mais afeto à condição humana do que a amizade.

2 - O núcleo central do ensaio é constituído pelas noções de "regra", de "lei" ou de "norma". O amor é, desde que os homens saíram do domínio da natureza, o reino do interdito. Mas como regrar e controlar o que, dada sua própria natureza, vive e se alimenta da transgressão? Este é o paradoxo evidenciado e explorado por Montaigne. Pretendo, então, apresentar uma "leitura filológica" do capítulo, que toma como fio condutor os termos acima e seus correlatos, e que se divide em dois eixos: num deles Montaigne reflete sobre o (insensato) projeto dos homens de impor leis e normas às mulheres; no outro, o que está em jogo é o auto-controle dos homens.

4 Hesíodo. Teogonia, 120-122.

5 "E sei que a poesia está para a prosa / Assim como o amor está para a amizade / E quem há de negar que esta lhe é superior?" - Canção "Língua", de Caetano Veloso.

6 Refiro-me ao método proposto por Jules Brody em Lectures de Montaigne. 
A conclusão do presente artigo é, de fato, uma terceira tese, que se diferencia das outras duas por seu caráter mais geral. Embora "Sobre versos de Virgílio" seja o capítulo que mais fala das mulheres e embora seu autor pretenda que o assunto as faça levar os Ensaios ao recesso de seus aposentos ${ }^{7}$, o texto não se dirige às mulheres nem faz delas seu principal objeto. Aqui também Montaigne fala de si, enquanto homem, no masculino. Parte integrante e confessamente essencial de seu autorretrato, e no qual ele cumpre a promessa de pintar-se nu como um canibal, "Sobre versos de Virgílio" é, principalmente, uma reflexão sobre a condição masculina e suas leis, e ganha muito se for lido como tal.

\section{Amizade e amor}

Em "Da amizade", Montaigne, avaliando as diversas relações humanas, escreve:

Não se pode comparar com essa [a amizade] nossa afeição pelas mulheres (...) Assim, essas duas paixões entraram em mim com conhecimento uma da outra, porém jamais com comparação: a primeira mantendo sua rota com um voo alto e altivo, e olhando esta outra ir avançando muito ao longe abaixo dela (I, 28, 186/278).

As razões de uma afirmação tão radical são várias e podem ser encontradas nos dois capítulos referidos até agora: a relação amorosa com as mulheres embora compartilhando com a amizade o fato de ser uma escolha livre (ao contrário do casamento, que é imposto socialmente ${ }^{8}$ ) - é necessariamente passageira, volúvel, e "nos prende apenas por um fio", a atração sexual. O amor "é apenas um desejo desvairado perseguindo o que nos foge", cuja "fruição o arruína" (I, 28,186/278). "Tão logo elas são nossas, já não somos mais delas" (III, 5, 881/144). Sentimento ambíguo, depende dos jogos e da recusa; e Vênus ainda - escreve Montaigne citando Catulo - "mistura um doce amargor aos cuidados amorosos" (I, 28, 185/277). A natureza do amor é bem descrita ao final de "Sobre versos de Virgílio": Vênus é uma deusa inconstante e insaciável, que não hesita em abandonar o amante para preservar

7 "Aborrece-me que meus ensaios sirvam às mulheres apenas como alfaia comum e como alfaia de sala. Este capítulo tornar-me-á da alcova" (III, 5, 847/93). Montaigne cita (sempre em latim) escritores que descrevem as relações amorosas com um linguajar bem direto e explícito, como Juvenal e Catulo.

8 Sobre casamento e sexo, Montaigne escreve, seguindo nisso seu tempo: "São dois desígnios que têm caminhos distintos e não confundidos. Uma mulher pode entregar-se a um certo indivíduo que não desejaria em absoluto desposar" (III, 5, 853/102). Como escreve Desan: "Fazer filhos representa uma atividade social, e não sexual; assim Montaigne separa irremediavelmente o casamento dos prazeres do corpo e do sentimento" (Verbete "Mariage". In: Dictionnaire, p. 635). 
a força do amor: "não é uma paixão puramente corporal, ela continua a viver após a saciedade; não se pode definir-lhe nem satisfação duradoura nem um final" (III, 5, 885/150). Já a amizade é uma relação completa em si mesma. Finalmente, sendo a alma das mulheres incapaz de cultivar o "amplexo de um laço tão estreito e tão duradouro" que é a amizade, o ideal de uma relação da qual participariam ao mesmo tempo corpo e alma, "em que um homem se envolvesse por inteiro", é irrealizável (I, 28, 186/278-279). Tal afirmação de Montaigne contraria seu muito estimado Plutarco, para o qual a relação conjugal, "na qual Eros e Afrodite convivam harmoniosamente, constitui o mais autêntico exemplo de união". ${ }^{9}$ As fronteiras estão bem traçadas: a amizade perfeita acontece entre homens, o amor sexual se passa entre homem e mulher.

Ainda outros pontos atestam a superioridade da amizade:

1. Ela é rara e acontece entre almas nobres -

(...) essa amizade que, enquanto Deus quis, alimentamos entre nós, tão íntegra e tão perfeita que sem a menor dúvida não se lê muito sobre outras iguais, e entre nossos contemporâneos não se vê o menor indício de sua prática (I, 28, 275/184) -,

já o amor é comum: "Meu pajem faz amor e entende-o (III, 5, 874/134). 2. O amor é mais perfeito na poesia do que na vida: "Vênus não é tão bela totalmente nua, e viva, e anelante, como o é aqui, em Virgílio" (III, 5, 849/96) -, já a amizade não encontra uma descrição à sua altura: “[A] (...) os próprios discursos que a Antiguidade nos deixou sobre esse assunto parecem-me frouxos em comparação com o sentimento que tenho a esse respeito" (I, 28, 192/287).

3. A amizade consiste em uma união perfeita:

[A] (...) quintessência de toda essa mistura, que, tendo se apossado de toda a minha vontade, levou-a a mergulhar e perder-se na sua; [C] que, tendo se apossado de toda a sua vontade, levou-a a mergulhar e perder-se na minha, com a mesma fome, com a mesma convergência” (I, 28, 189/282).

Já o amor preserva suas distâncias:

[B] De resto, nessa troca (marché), eu não me entregava por inteiro; comprazia-me, porém não me esquecia: preservava por inteiro esse pouco de senso e de discernimento

9 Carlos A. Martins de Jesus. "Introdução" In: PLUTARCO, Obras morais, p. 14. Na tradição greco-latina, Eros é associado ao amor entre homens, e Afrodite (Vênus) ao amor entre homem e mulher, de componente marcadamente sexual. 
que a natureza me deu, para servir a elas e a mim, um pouco de emoção, mas nada de loucura (III, 5, 891/159).

Poderíamos continuar com a comparação: a amizade é pura harmonia, o amor mais parece uma guerra: "O valor da vitória mede-se pela dificuldade" (III, 5, 862/116), e assim por diante. No entanto, a leitura de "Sobre versos de Virgílio" pode, se não subverter, pelo menos relativizar este quadro:

1. Em relação à sua identidade, Montaigne afirma que a perda do amigo foi profundamente desestruturadora: "[A] Já estava tão afeito e habituado a ser um de dois em tudo, que me parece não ser mais que meio" (I, 28, 193/289). Mas a masculinidade, anatomicamente falando, não perde neste quesito: "Cada uma de minhas partes faz-me tão igualmente eu quanto qualquer outra. E nenhuma outra me faz mais propriamente homem do que essa." (III, 5,887/ 154).

2. Montaigne confessa que só o amor seria capaz de aliviá-lo das tristezas da velhice e renovar-lhe o ânimo, tirando-o do estado melancólico: "não tenho outra paixão que me mantenha o alento" (III, 5, 893/162).

3. Deixando o ponto de vista autobiográfico e passando para o geral, temos que o amor, se é comum, é também onipresente: "Todo o movimento do mundo dedica-se e se rende a esta união: é uma matéria infusa em toda parte, é um centro para o qual se voltam todas as coisas" (III, 5, 857/108). Simples "prazer de descarregar os vasos" (III, 5, 877/137), o amor é também a força que move o mundo - e por isso é possível arriscar a hipótese de que Vênus, embora inferior, seja mais necessária do que a philía. O amor não é uma força que eleva; de fato, ele nunca transcende a natureza, não leva ao ideal ou ao divino, é mesmo uma "ocupação vã, inconveniente, vergonhosa e ilegítima” (III, 5, 891/159). Mas é a própria força da vida, simplesmente.

As muitas aproximações entre sexo e natureza, compreendendo-o como algo que os seres humanos compartilham com os animais, apontam para o fato de que o sexo ocupa um lugar fundamental, se não na vida dos sábios e dos santos, pelo menos na vida de Montaigne e das pessoas comuns, vida esta regida pelo prazer:

As pessoas mais sábias podem criar para si um repouso totalmente espiritual, mantendo a alma forte e vigorosa. Eu, que a tenho comum, preciso ajudá-la a sustentar-me pelas comodidades corporais (...) Temos que segurar com todos os nossos dentes e unhas o uso dos prazeres da vida que os anos nos arrancam das mãos, uns após os outros (I, 39, 246/367). 
Os leitores de Montaigne sabem o quanto o prazer lhe é essencial: “(...) na própria virtude o fim último que visamos é a volúpia" (I, 20, 82/120). Mas há mais: baixo e comum, o amor, enquanto tal, não encaminha ninguém à virtude; renegá-lo, porém, abre a porta a todos os vícios - o que mostra que o capítulo tem uma importante dimensão ética. Paixão essencial à natureza humana, sua denegação é perigosa: "Que monstruoso animal, que tem horror de si mesmo, a quem seus prazeres pesam” (III, 5,141/879).

Destaco um fato que parece advogar pela superioridade da amizade: ela é singular e tem um nome, no caso, Etienne de La Boétie, o amigo cuja importância para a vida de Montaigne e para a escrita dos Ensaios é indiscutível. Já o amor não tem rosto nem nome: nenhuma Beatriz ou Dulcinéia, nenhuma Julieta, mas "elas", les femmes, no plural. Coisa de machista que trata as mulheres como simples objetos? De forma alguma: para as mulheres, da mesma forma, existem "os homens" - e isso se deve à natureza do amor, às idas e vindas do desejo, pois o amor é algo que "só se paga na mesma espécie de moeda" (III, 5, 894/163). O modelo de Montaigne neste assunto são as deusas e os deuses do Olimpo e isto por si só já diz muita coisa.

Mesmo que não haja, para Montaigne, a mulher imprescindível, o amor em si o é. Daí que as mulheres, como gênero, ocupem este lugar tão tenso e essencial na escrita dos Ensaios. Tomada na particularidade, nenhuma história de amor faz sombra à da amizade com La Boétie, é certo; mas tomada a narrativa da vida como um todo, o amor como força, como paixão, como potência, não é menos importante que a amizade no autorretrato de Montaigne. A ausência do amor na velhice não é menos destruidora de sua integridade que a trazida pela morte de la Boétie, como vimos - e talvez o seja mais.

Quanto ao autorretrato, sabemos que a promessa de pintar-se "inteiro e nu", feita no início do livro, cumpre-se, pelo menos no que diz respeito ao nu, nesse capítulo já tardio dos Ensaios. Afirmando que a natureza não o favoreceu, ele recorre a um poeta latino anônimo para nomear e descrever a "parte" que faltava pintar. (III, 5, 877/153-154).

A amizade se passa toda na alma, o amor se passa no corpo (mas não apenas lá: há a fantasia, a imaginação, a poesia etc.). Dado que o ser humano é uma junção e uma mistura, não é assim tão evidente que algo afeto apenas à alma, como a amizade, possa sobrepujar o amor.

\section{As regras do amor}

Tomando, por exemplo, a direta definição do amor como "o prazer de descarregar seus vasos", poderíamos ser levados a pensar que, finalmente, o 
amor é algo muito simples e natural. Nada mais equivocado. Desde o início do capítulo, o amor surge como um problema, pois, dado que os homens se distanciaram das leis naturais - tais como se manifestam nos animais ou nos costumes dos canibais -, o amor ultrapassou o corpo e caiu na esfera do espírito e da imaginação, que são instâncias desestabilizadoras: "O corpo recebe as cargas que lhe pomos em cima exatamente como elas são, o espírito as estende e as pesa frequentemente à sua própria custa, dando-lhes a medida que bem the parece" (III, 10, 1007/334). ${ }^{10}$ Sobre os efeitos da imaginação sobre a sexualidade, vale a pena ler as divertidas passagens do capítulo "Da força da imaginação" (I, 21).

Desprovido da regulação natural, o amor é então submetido às regras artificiais dos costumes e das leis - elas também múltiplas e variadas, segundo as diferentes sociedades. Embora Montaigne descreva costumes de outros povos, nesse capítulo ele coloca em foco principalmente as regras de sua própria sociedade. A relação entre amor e regras sociais, não só em "Sobre versos de Virgílio", mas também em outros lugares dos Ensaios, é extremamente complexa. Por um lado, o ensaísta acusa a espécie humana de, com suas inúmeras proibições, pretender negar sua natureza sexual e corpórea, gerando sofrimentos ${ }^{11}$; por outro, declara que os cerceamentos à sexualidade são essenciais, pois a proibição aguça e alimenta o desejo ${ }^{12}$. De forma que o pudor é, paradoxalmente, um aliado da tentação; já a total liberdade da natureza (ou do casamento - III, 5, 854/103) não é assim tão sedutora. Retomando um tema clássico, ele elogia a moderação e a temperança como princípios de regulação; afirma, porém, que a própria moderação tem que ser moderada, pois não é sempre recomendável: "A sensatez tem seus excessos, e não necessita menos de moderação do que a loucura" (III, 5, 841/84). Enfim, Vênus e as leis se amam e se odeiam; no entanto, a frase de São Jerônimo

10 "O corpo, exceto por algo a mais ou a menos, tem apenas um andamento e um vinco. A alma é mutável em toda espécie de formas, e submete a si e a seu estado, seja ele qual for, as sensações do corpo e de todos os outros acidentes" (I, 4,57/83). Muitos intérpretes já ressaltaram que em Montaigne, diferentemente da tradição filosófica, o corpo, ao contrário da alma, é o lugar da ordem e da regra naturais. Mais recentemente B. Sève retomou com acuidade este ponto, analisando o tema do "espírito" nos Ensaios. O corpo estaria ligado a um "princípio de regulação" e o espírito é um "princípio de desregramento" (SĖVE, p. 216). Os animais da "Apologia de Raymond Sebond" seguem seus instintos sem serem perturbados pelas fantasias da razão, os canibais seguem a natureza sem os desregramentos trazidos pelos artifícios, eis os exemplos das "leis do corpo", cujo principal efeito é afastar a infelicidade. Distanciados do paradigma natural, homens e mulheres não mais conseguem encontrar satisfação na atividade corpórea e têm que lançar mão de artifícios e fantasias.

11 Por exemplo: "Acaso não somos muito brutos ao chamar de bestial a ação que nos faz?" (III, 5, 878/139).

12 Por exemplo: "Não seria a própria Vênus que argutamente encareceu assim sua mercadoria, pela manipulação das leis, sabendo que este é um prazer tolo se não o valorizassem por meio da imaginação e da dificuldade?" (III, 5, 871/129). 
"Amor ordinem nescit"13, citada e comentada ao final do capítulo, vem atestar a superioridade da deusa sobre os homens.

\section{As leis dos homens}

Boa parte do capítulo diz respeito ao controle e aos limites que os homens pretendem impor às mulheres na forma da continência. Segundo Montaigne, tal atitude é, não apenas questionável em sua autoridade, mas absurda, porque fecha os olhos à realidade do desejo e capacidade femininos:

As mulheres não estão totalmente erradas quando rejeitam as regras de vida que são introduzidas no mundo, pois foram os homens que as fizeram, sem elas. (...) na opinião de nosso autor [Isócrates?], tratamo-las sem consideração nisso: depois de termos reconhecido que são, sem comparação, mais capazes e ardentes do que nós nos feitos do amor (...), fomos aquinhoá-las particularmente com a continência, e sob as penas derradeiras e extremas. (III, 5, 854/103-105 - grifo nosso).

O ensaísta denuncia a desproporção entre o que é exigido às mulheres e aos homens, sendo que ambos estão igualmente sujeitos ao império do desejo, uma "sede comum" descrita com fortes imagens neste capítulo (III, 5, 859/111112). Ora, manter a castidade exige maior força do que ir para a guerra:

E elas de bom grado se proporão a ir buscar ganhos no tribunal e renome na guerra ao invés de, em meio à ociosidade e às delícias, terem de fazer uma guarda tão difícil. Acaso [os homens] não veem que não há mercador, nem procurador, nem soldado que não deixe sua tarefa para acorrer àquela outra, e também o carregador e o sapateiro, por mais estafados e extenuados que estejam? (III, 5, 861/113).

Outro equívoco é querer que as mulheres sejam castas e, ao mesmo tempo "saudáveis, vigorosas, robustas" (III, 5, 855/105) - esquecendo-se que só a doença e a fraqueza corporal podem vencer o desejo.

As regras dos homens são absurdas, pois se opõem à natureza; mas também pouco inteligentes, pois erram seu alvo. Por exemplo, mandam esconder e cobrir os órgãos genitais, com o intuito de diminuir a tentação; no entanto, como já vimos, acabam por provocar o efeito contrário, atiçando a curiosidade e a imaginação. Em nome da virtude estimulam o vício, pois fazem com que as mulheres finjam e mintam, aparentando uma frigidez de resto inacreditável (Montaigne não deixa de zombar disso - III, 5, 865-867/120122). São, também, vagas: "Não sabemos circunscrever-lhes com precisão as ações que lhes proibimos. Temos que conceber nossa lei sob palavras gerais 
e incertas". E, o que se quer, finalmente, é anular as mulheres: "É preciso que elas [as mulheres] se tornem insensíveis e invisíveis para satisfazer-nos" (III, $5,868 / 124)$.

$\mathrm{Na}$ maior parte das vezes, o feitiço se volta contra o feiticeiro, pois as regras dos homens, ao exigir o pudor e a castidade das mulheres, criaram grandes dificuldades não só para elas, mas para eles mesmos: "Pois esta norma que lhes ordena que nos abominem porque as adoramos e nos odeiem porque as amamos é indiscutivelmente cruel..." (III, 5, 862/115). De modo que é preciso saber interpretar as recusas e, em alguns casos, contentar-se com a virtude das moças.

A motivação por detrás de tudo isso é preocupação irracional dos homens com sua reputação, como se pudessem ter a honra manchada pelos atos de sua mulher. Na época em que escreve Montaigne, o controle da sexualidade feminina liga-se, sobretudo, à preocupação com a geração de filhos legítimos. ${ }^{14}$ Montaigne refere-se explicitamente a esse ponto apenas uma vez, colocando-o em perspectiva: "Quanto à confusão de filhos, além de os mais sérios legisladores prescrevem-na e buscarem-na em suas formas de governo (...)" (III, 5, 864-865/119). Seu tom em relação à preocupação dos maridos com a fidelidade das esposas é, em geral, jocoso: "É preciso ter engenhosidade para evitar este conhecimento penoso e inútil" (III, 5, 869/126); "Cada um de vós fez de alguém um corno, ora, a natureza é toda feita de reciprocidades [a natureza se iguala, em compensações e vicissitudes] (...)" (III, 5, 870/127). O julgamento final sobre a pretensão do gênero masculino não deixa dúvida: "é loucura tentar refrear nas mulheres um desejo que lhes é tão lancinante e tão natural" (866/122). As regras, que deveriam favorecer a moderação, acabam por introduzir a total falta de medida. Montaigne acusa seu tempo de perder o que realmente importa para a virtude, ao considerar a lascívia como um vício muito maior do que realmente é: a obsessão com os pequenos vícios do sexo faz com que o combate aos verdadeiros e grandes vícios seja deixado de lado.

Dito isso, nem tudo está dito.

\section{As leis de Vênus}

Como não podia deixar de ser, há outra perspectiva sob a qual Montaigne vê as leis e as regras ligadas ao sexo e que se relaciona com o modo como ele pensa, mais amplamente, o tema das leis e dos costumes. Sabemos que sua denúncia da irracionalidade sobre a qual se assentam costumes e leis não 
implica nenhuma proposta de revolução, pelo contrário - ele considera todo projeto de mudança radical pretensioso e perigoso, condenando sem meias palavras a reforma protestante. Do mesmo modo, na questão sexual, o crítico das regras não defende uma liberação geral e nem propõe destituir o sexo masculino de seu papel de legislador. Há apenas uma intenção confessa neste ensaio: "aliviar a condenação" que pesa sobre a sexualidade (III, 5, 889/156).

A recusa implícita de uma eventual "revolução sexual" leva em conta o outro lado das leis e das proibições, ao qual já nos referimos: o fato de a dificuldade tornar a conquista mais valiosa. Não somos regidos pelas coisas, mas por nossas opiniões sobre as coisas e o amor não é exceção: "a compra dá valor ao diamante, e a dificuldade à virtude, e a dor à devoção, e o amargor ao medicamento" (I, 14, 62/91). Montaigne expressa essa ideia misturando o linguajar da súplica ao da guerra: "por mais que juremos e ameacemos e nos queixemos, mentimos: amamo-las mais por isso [por causa das recusas]" (III, 5, 862/115). E, ainda, deliciosamente: "[as mulheres] devem sempre fugir diante de nós, e me refiro até mesmo às que têm de deixar-se apanhar" (III, $5,884 / 149)$. Portanto, as leis e as regras dos homens não são simplesmente fruto do temor ou da falta de tino deles; elas são, de fato, ditadas pelo amor: "Não seria a própria Vênus que argutamente encareceu assim sua mercadoria pela manipulação das leis, sabendo como esse é um prazer tolo se não o valorizassem por meio da imaginação e da dificuldade?" (III, 5, 871/129). Enfim, nesta dinâmica, os homens, que pareciam os senhores das leis, não são senão seus servos e "joguetes dos deuses", pois também eles sofrem com as leis que impuseram às amadas. As leis do amor afetam a todos, homens e mulheres, pelo bem do amor, cuja glória "é que todas as outras regras cedem às suas" (III, 5, 871/129).

\section{As leis de Montaigne}

Também como não poderia deixar de ser, o capítulo expõe as regras próprias de Montaigne sobre este assunto. Devo deixar de lado, pois o tema exigiria outro artigo, as passagens explicitamente autobiográficas, nas quais ele descreve suas atitudes nos jogos amorosos, considerando-as, sem modéstia, exemplares. De uma forma mais geral, o remédio indicado pelo ensaísta, para não se deixar dominar por Vênus, essa grande senhora, está no recurso à natureza. Trata-se de encarar o amor naquilo que ele tem de natural, ao invés de divino ou demoníaco, e de conceder ao corpo o seu lugar. Nada no capítulo sugere o elogio da paixão que se avizinha da morte ou da perda de si.

Apresentando-se como natural, o amor "embrutece e animaliza", perturbando as operações da alma (III, 5, 877/138). Não cabe, porém, 
horrorizar-se com isso, e, como vimos, mesmo a lei da temperança e do comedimento deve adequar-se à situação, fazendo a alma assistir o corpo em seus prazeres. Não se deve sobrecarregar por artifícios as misérias de nossa condição e, sobretudo, não se deve desprezar a condição humana - e daí a importância do distanciamento crítico e de certa desconfiança em relação aos costumes e comportamentos usuais. Isto significa, sobretudo, não conferir um lugar absoluto nem à perspectiva da lei, nem à da transgressão, mas aceitar que o amor é constituído por essas duas forças.

A natureza é, nesse capítulo como em outros, o remédio para os descaminhos do ser humano. É ela quem coloca o amor em pauta como aquilo sobre o que se deve falar; é o aspecto natural do amor que fundamenta a causa que Montaigne move a seu favor. Digamos, assim, que, tal como o homem de Bacon vence a natureza obedecendo-lhe, também os homens devem acolher as leis do amor, sua imperiosa força e necessidade, usando-as em seu próprio benefício. É ainda a natureza que, ao final do capítulo, vem atestar a igualdade entre homens e mulheres, pois Montaigne atribui a maior parte das diferenças entre os gêneros à educação e ao uso.

\section{Conclusão}

A leitura de "Sobre versos de Virgílio" centrada nas noções de "regra", "lei" e "norma" mostra que, embora aparente ser um capítulo dedicado às mulheres, o que se lê, finalmente, é a reflexão de um homem sobre as crenças e práticas masculinas - de resto, bastante desabonadora para o seu gênero. Como acontece em geral nos Ensaios, aqui também Montaigne fala do outro para falar de si, ou seja, fala das mulheres para falar dos homens e colocá-los em questão. Neste sentido "Sobre Versos de Virgílio" é um texto não tanto sobre a condição humana, mas sobre a condição masculina.

\section{Referências Bibliográficas}

BLANCHARD, Mark E. Popée voilée. In : Trois portraits de Montaigne. Essai sur la représentation à la Renaissance. Paris: Librairie A.-G. Niset, 1990.

BOWEN, Barbara C. "Montaigne's anti-Phaedrus: Sur des vers de Virgile" (Essais, III, V). In : The Journal of Medieval and Renaissance Studies 5, 1975, pp.107-21. BRODY, Jules. Lectures de Montaigne. Lexington: French Forum, 1982.

CHARPENTIER, F. “Amour”. In: DESAN, Philippe (dir). Dictionnaire de Michel de Montaigne. Paris Honoré Champion, 2004. p.30-33.

DESAN, Philippe. "Mariage". In: DESAN, Philippe (dir). Dictionnaire de Michel de Montaigne. Paris Honoré Champion, 2004. p.635-637. 
JESUS, Carlos A. Martins de. "Introdução" In: PLUTARCO. Obras Morais. Diálogos sobre o amor. Relatos de amor. Tradução do grego, introdução e notas de Carlos A. Martins de Jesus. Coimbra: Centro de Estudos Clássicos da Universidade de Coimbra, 2009, pp.7-40.

HESÍODO. Teogonia (Tradução Jaa Torrano). São Paulo, Iluminuras, 1991.

MONTAIGNE, M. Les Essais. Ed. Pierre Villey. Paris: PUF, 1988. 3 vol. (Col. Quadrige)

. Os ensaios. (Tradução Rosemary Costhek Abílio). São Paulo: Martins Fontes, 2000-2001, 3 vols.

NAKAM, Géralde. Langage de l'esprit, langage du corps dans les derniers "essais" des Essais. In : Montaigne : la manière et la matière. Paris, Ed. Klincksieck, 1991, pp. 195-204.

SÈVE, Bernard. Montaigne. Des Règles pour l'esprit. Paris, PUF, 2007. 